\title{
AVALIAÇÃO DO ESTADO NUTRICIONAL DE BAILARINAS DA DANÇA DO VENTRE
}

\author{
Evaluation of nutritional aspects of belly dancing ballerinas
}

\author{
Idalina Maia Ribeiro
}

\section{RESUMO}

A Dança do Ventre é uma dança feminina que desenvolve a graça, a sensualidade e a alegria de ser mulher. $O$ presente estudo teve como objetivo a identificação da correlação existente entre a ingestão alimentar e a composição corporal de baillarinas da Dança do Ventre, de um grupo autônomo, denominado Yalabina, do Rio de Janeiro. Foram estudadas 12 bailarinas, que apresentavam, em média, idade de 31,58 \pm 5,40 anos e uma experiência prévia de 5,18 \pm 0,60 anos com a Dança do Ventre. Para avaliação do estado nutricional, utilizou-se o método antropométrico (IMC) e, para avaliação da ingestão alimentar, utilizou-se o método de registro alimentar, através do qual cada uma das bailarinas descreveu, detalhadamente, a quantidade dos alimentos e bebidas ingeridos durante três dias, sendo um deles no final de semana. Os resultados obtidos foram analisados estatisticamente através do cálculo das médias, desvios-padrão e variância (Anova One-Way) para determinação do perfil antropométrico e para análise do consumo alimentar, através da quantificação dos macronutrientes ingeridos respectivamente. Não houve diferença estatisticamente significativa $(p>0,05)$ entre a avaliação da ingestão alimentar registrada nos três dias. Já em relação às recomendações da World Health Organization (2003), as dietas foram classificadas como hipercalóricas, normoglicídicas, hiperprotéicas e hiperlipídicas, nos três dias. Conclui-se que os resultados obtidos apontam a necessidade de uma intervenção nutricional, principalmente no que diz respeito ao consumo de energia, proteínas e lipídios.

Palavras-chave: Perfil Antropométrico, Consumo Alimentar, Bailarinas.

\begin{abstract}
Belly Dancing is a feminine dance that develops the grace, the sensuality and the joy of being a woman. The present study had as objective the identification of the existing correlation between the alimentary ingestion and corporal composition of ballerinas of Belly Dancing of an independent group called Yalabina, in Rio de Janeiro. Twelve dancers had been studied, average of age of $31.8 \pm 5.40$ years and a previous experience of $5.18 \pm 0.60$ years with Belly Dancing. In order to evaluate the corporal composition, the anthropometric (IMC) method was used, and to evaluate the alimentary ingestion, the method of alimentary register was used, in which the dancers at great length described the amount of food and drinks ingested during three days, including one day of their weekend. The results had been analyzed statistically through the calculation of averages, standard deviation and variance (Anova One-Way) for the determination of the anthropometric profile and analysis of the alimentary consumption through the quantification of the macronutrients ingested respectively. There was no statistically significant difference ( $p>$ 0.05 ) between alimentary inquiry evaluated during three days consecutively. However, in relation to the World Health Organization (2003), the diets had been classified as hypercaloric, normoglicidic, hyperproteic and hiperlipidic in those three days. Therefore, the results point out the necessity of a nutritional intervention, mainly when it comes to energy consumption, proteins and lipids.
\end{abstract}

Key words: Anthropometric Profile, Alimentary Consumption, Dancers.

\section{INTRODUÇÃO}

A Dança do Ventre é uma dança feminina que desenvolve a graça, a sensualidade e a alegria de ser mulher. Envolve movimentos que lembram uma serpente, sinuosos, ondulantes, às vezes lentos ou ágeis. É uma arte milenar que une condicionamento físico, técnica, expressão corporal e beleza plástica. Os povos nômades, ciganos (gawazi), beduínos e tuaregs, contribuíram para difundir a cultura e a tradição da dança em várias regiões do mundo

Universidade Estácio de Sá - Rio de Janeiro - RJ - Brasil.

Recebido em 22.06.2008. Aceito em 17.09.2008.

Revista de Educação Física 2008 Dez; 143:35-40. Rio de Janeiro (RJ) - Brasil. 
árabe. A Dança do Ventre popularizou-se e foi levada para os palácios e haréns, perdendo, assim, seu caráter sagrado. Atualmente, faz parte do folclore e da cultura de países do Oriente Médio e do Norte da África ${ }^{1}$.

No contexto atual, a Dança Oriental proporciona auxílios adicionais, em comparação com outros tipos de danças, pois a mesma envolve um leque de movimentos que trabalham diversos grupos musculares, a expressividade, a elegância, a presença em cena, a musicalidade, os deslocamentos e as temáticas folclóricas, que permitem à mulher transportar-se no tempo, nos lugares e 'brincar' com os trajes e acessórios de forma única. Na Dança Oriental, trabalha-se priorizando a região do ventre, região esta que somatiza as emoções ${ }^{2}$. Os movimentos da dança são benéficos para todo o corpo, desde os olhos até as articulações e os tendões. Além disso, sua sincronicidade enseja uma maior concentração, estimulando uma rápida melhora na memorização ${ }^{1}$.

A Dança do Ventre destina-se, unicamente, ao corpo feminino, enfatizando os músculos abdominais e os movimentos de quadris e tórax. Ela é praticada com os pés descalços, firmados no solo, caracterizando-se pelos movimentos suaves, fluidos, complexos e sensuais do tronco, alternados com movimentos de batida e tremido ${ }^{3}$.

De acordo com Cestari ${ }^{4}$, por ser uma atividade aeróbica, quem pratica esta dança pode queimar calorias durante as aulas e as apresentações. Qualquer pessoa pode praticar, não havendo restrição de idade e nem de peso. Vale ressaltar que a Dança do Ventre não aumenta o abdômen, como muitos presumem. A postura errada, durante o movimento dos músculos, pode ocasionar dores lombares, facilitar o acúmulo da gordura embaixo do ventre, podendo este ser seguido de flacidez.

O exercício físico, isoladamente, sem o acompanhamento de uma dieta equilibrada, não resulta em resultados eficientes. Há uma importante relação entre a nutrição e a atividade física, uma vez que a capacidade de rendimento do organismo melhora com uma nutrição adequada, através da ingestão equilibrada de nutrientes ${ }^{5}$.

O American Dietetic Association ${ }^{6}$ ressalta os efeitos benéficos de uma dieta equilibrada e da prática de exercícios físicos na prevenção de doenças crônicas. Embora a literatura já acumule quantidade apreciável de informações sobre a interação entre atividade física e nutrição, a maioria das pessoas ignora qual seria sua nutrição adequada ${ }^{7}$.

Cuppari et al. ${ }^{8}$ salientam que a seleção de alimentos é muito complexa, sendo influenciada por vários fatores. Embora se saiba que quando os alimentos não estão disponíveis é bem provável que ocorram deficiências, por outro lado, a abundância, por si só, não assegura ótima nutrição, devido ao componente comportamental que determina a escolha de alimentos. Mediante uma alimentação variada, em quantidades adequadas, pode-se obter uma dieta equilibrada, ou seja, a que proporciona os nutrientes importantes para atender as necessidades do organismo.

De acordo com Shils et al. ${ }^{9}$, avaliar corretamente o estado nutricional é o primeiro passo no processo de intervenção para a boa nutrição, pois permite reconhecer as alterações por perda ou excesso e, deste modo, orientar, na saúde e na doença, o melhor planejamento nutricional.

A antropometria é a medida do tamanho corporal e de suas proporções. Trata-se de um dos indicadores diretos do estado nutricional e fornece, de maneira rápida e não invasiva, informações a respeito dos compartimentos corporais, particularmente gordura e músculo, a curto e a longo prazo ${ }^{10}$. Portanto, o perfil ou o estado nutricional encontrado servirá de alerta para um possível estado de desnutrição ou obesidade ${ }^{11}$.

O estado nutricional reflete o grau no qual as necessidades fisiológicas dos nutrientes estão sendo alcançadas, ou seja, a relação entre o consumo de alimentos e as necessidades nutricionais do indivíduo ${ }^{12}$. A avaliação da ingestão de nutrientes é parte da avaliação nutricional, sendo utilizada para a tomada de decisão quanto à adequação do consumo alimentar do indivíduo. Os métodos propostos para avaliação da adequação da ingestão de nutrientes, de cada uma das bailarinas analisadas nesse estudo, estão de acordo com os valores estabelecidos pelo World Health Organization ${ }^{13}$.

O presente estudo teve, como objetivo, identificar a correlação existente entre a ingestão de alimentos e a composição corporal de bailarinas da Dança do Ventre.

\section{METODOLOGIA}

Para o desenvolvimento desse trabalho, empregou-se metodologia exploratória por meio de uma pesquisa do tipo descritiva. Os procedimentos utilizados foram: a) 
característica da amostra; b) coleta de dados e instrumentos utilizados; c) tratamento estatístico.

\section{Características da amostra}

Participaram do estudo 12 bailarinas da Dança do Ventre, na faixa etária entre 24 a 36 anos, de um grupo autônomo da equipe Yalabina, do Rio de Janeiro.

\section{Coleta de dados e instrumentos utilizados}

Foi realizada avaliação do estado nutricional e do consumo alimentar da amostra.

Para a avaliação do estado nutricional, foram aferidos o peso e a estatura. Para a mensuração do peso, as bailarinas foram orientadas a estarem vestidas com roupa de ginástica, descalças, com calcanhares unidos e paralelos, braços relaxados, posicionando-se em pé, no centro da balança e de forma ereta ${ }^{8}$. O instrumento utilizado foi uma balança digital calibrada, de plataforma, da marca Plenna, modelo MEA- 03140 (Futura), com capacidade de aferição de peso de até $150 \mathrm{~kg}$.

Para a aferição da estatura, deveriam estar em pé, descalças, costas retas e braços estendidos ao lado do corpo, com olhos fixos para frente ${ }^{8}$. Para mensuração de estatura, foi utilizada uma fita antropométrica, fixada na parede, da marca Mabis, em fibra de vidro, com $150 \mathrm{~cm}$.

A combinação desses dados permitiu determinar o índice de massa corporal (IMC), expresso em $\mathrm{kg} / \mathrm{m}^{2}$, calculado para cada bailarina de acordo com os critérios recomendados, internacionalmente, para diagnósticos individuais e coletivos da população adulta ${ }^{13}$.

Para avaliação do estado nutricional, cada bailarina foi instruída para descrever, de forma detalhada, a quantidade de todos os alimentos e bebidas ingeridas, durante três dias, por meio do registro alimentar, sendo que dois dias foram de segunda a sexta-feira e um, durante o final de semana (sábado ou domingo). As informações coletadas do registro alimentar serviram para avaliar a ingestão média dos macronutrientes (carboidratos, proteínas e lipídios). 0 consumo alimentar foi confrontado com as recomendações nutricionais específicas para cada bailarina, de acordo com os valores preconizados pela World Health Organization ${ }^{13}$, visando avaliar o grau de adequação.

\section{Tratamento estatístico}

Para a análise estatística, foi utilizado o cálculo das médias e desvio-padrão de todas as variáveis descritas, associadas à amostra, referentes ao estado nutricional e ao consumo alimentar.

Os dados foram armazenados em banco de dados, criado por meio do programa Microsoft Excel, sendo analisados, estatisticamente, através da variância Anova One-Way. Foram considerados que não diferem significativamente os valores de $p>0,05$.

Tendo sido fechado o diagnóstico do estado nutricional, a partir do índice de massa corporal, e após a conclusão da análise do consumo alimentar que determinou os grupos em termos de distribuição percentual média de macronutrientes em relação ao Valor Energético Total (VET), nos três dias, realizou-se a verificação da existência de uma correlação, positiva ou negativa, entre estas duas variáveis.

\section{RESULTADOS E DISCUSSÃO}

As bailarinas analisadas apresentavam uma média de idade de 31,58 $\pm 5,40$ anos e experiência prévia de 5,18 \pm 0,60 anos com a Dança do Ventre. O peso corporal médio foi de $64,00 \pm 14,60(\mathrm{~kg})$ e a estatura, de 1,62 $\pm 0,05(\mathrm{~m})$. Verificou-se que $100 \%$ das bailarinas relataram realizar a Dança do Ventre duas vezes por semana. Com base no tipo e no número de vezes por semana que a atividade física era realizada, pode-se classificá-la como atividade aeróbica leve ${ }^{14}$.

Com relação ao estado nutricional das bailarinas, segundo o IMC, observou-se que estas se encontravam eutróficas ${ }^{13}$, tendo em vista que a média obtida foi 24,42 \pm $5,12 \mathrm{~kg} / \mathrm{m}^{2}$, conforme pode-se observar na TABELA 1.

Os resultados, apresentados no GRÁFICO 1, indicam que $22,06 \%$ das bailarinas apresentava IMC dentro da faixa de normalidade, sendo, portanto, classificadas como eutróficas. Em relação à desnutrição, ao sobrepeso e à obesidade classe II, observou-se uma prevalência de $19,50 \%, 28,78 \%$ e $35,32 \%$, respectivamente, quando comparadas com as recomendações estipuladas pela $\mathrm{WHO}^{13}$.

Estes dados diferem do estudo realizado, na Universidade de Brasília, por Mariz ${ }^{15}$, tendo em vista que o referido autor havia observado que a maioria das bailarinas avaliadas encontrava-se eutrófica e, uma minoria, acima do peso ou com baixo peso. 
TABELA 1

RESULTADOS DA AVALIAÇÃO DO ESTADO NUTRICIONAL DAS BAILARINAS.

\begin{tabular}{lcc}
\hline Variáveis & Média \pm DP & Recomendação segundo WHO (2003) \\
\hline Massa corporal $(\mathrm{kg})$ & $64,00 \pm 14,60$ & - \\
Estatura $(\mathrm{m})$ & $1,62 \pm 0,05$ & - \\
IMC $\left(\mathrm{kg} / \mathrm{m}^{2}\right)$ & $24,42 \pm 5,12$ & 18,5 a 24,9
\end{tabular}

\section{GRÁFICO 1}

AVALIAÇÃO DO ESTADO NUTRICIONAL, ATRAVÉS DO CÁLCULO DO IMC, DAS

BAILARINAS.

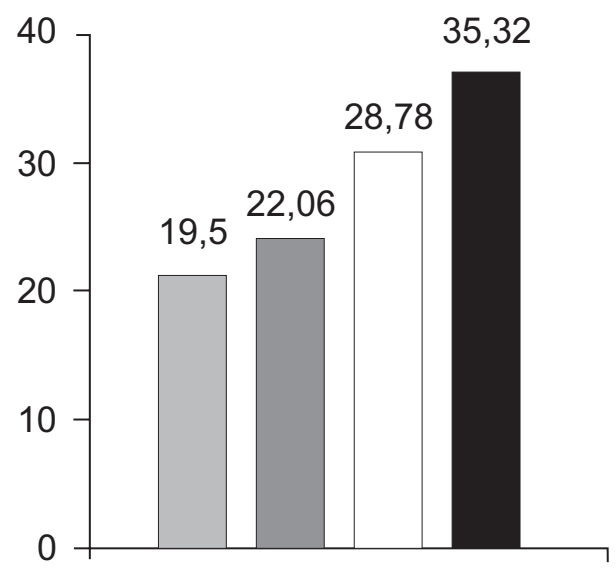

1

Foi avaliado o consumo médio de calorias $(1199,72$ $\mathrm{Kcal} / \mathrm{dia}$ ) e dos macronutrientes das bailarinas $(170,68 \mathrm{~g} / \mathrm{kg}$ de carboidratos, $42,43 \mathrm{~g} / \mathrm{kg}$ de proteínas e $38,58 \mathrm{~g} / \mathrm{kg}$ de lipídios).

As dietas foram classificadas como hipocalórica, normoglicídicas, hiperprotéicas e hiperlipídicas, frente às recomendações, conforme apresentado na TABELA 2. Não foram encontradas diferenças estatisticamente significantes, entre as bailarinas, quanto ao consumo de macronutrientes $(p>0,05)$. Os percentuais médios dos macronutrientes, em relação ao VET, e sua comparação com as recomendações da $\mathrm{WHO}^{13}$, estão representados na TABELA 3.

Pereira et al. ${ }^{16}$ ressaltam que o processo de modernização e de transição econômica, observado na maioria dos países, tem promovido alterações na industrialização da produção de alimentos, colaborando para o consumo de dietas ricas em proteínas e em gorduras, baixa em carboidratos complexos, o que, por sua vez, consiste em um importante fator para a gênese da obesidade.

Dessa forma, as bailarinas constituem um grupo de risco que merece cuidados especiais quanto à educação nutricional, considerando os hábitos alimentares inadequados que foram observados, tanto em relação ao consumo de energia, como a distribuição de macronutrientes na dieta.

Conforme pode-se observar no GRÁFICO 2, também foi observado um consumo excessivo (superior ao valor máximo da faixa recomendada de consumo) de proteínas e lipídios entre as bailarinas, sendo que o mesmo não foi

TABELA 2

AVALIAÇÃO DO CONSUMO ALIMENTAR DAS BAILARINAS.

\begin{tabular}{lccc}
\hline Total $(\mathbf{n}=\mathbf{1 2})$ & $\mathbf{1}^{\circ}$ dia (Quinta) & $\mathbf{2}^{\circ}$ dia (Sexta) & $\begin{array}{c}\mathbf{3}^{\circ} \text { dia (Sábado ou } \\
\text { Domingo) }\end{array}$ \\
\hline Energia (Kcal) & $1199,76 \pm 2388,36$ & $1199,75 \pm 2248,08$ & $1199,65 \pm 2360,22$ \\
Carboidratos (g) & $181,03 \pm 60,34$ & $165,13 \pm 55,04$ & $165,88 \pm 55,29$ \\
Proteínas (g) & $35,84 \pm 11,94$ & $47,26 \pm 15,75$ & $44,19 \pm 14,73$ \\
Lipídios (g) & $36,92 \pm 27,69$ & $38,91 \pm 29,18$ & $39,93 \pm 29,95$ \\
\hline
\end{tabular}


TABELA 3

ADEQUAÇÃO DO CONSUMO ALIMENTAR DAS BAILARINAS.

\begin{tabular}{lccc}
\hline Nutrientes & $\begin{array}{c}\text { Média dos três } \\
\text { dias }\end{array}$ & $\begin{array}{c}\text { Recomendações } \\
\text { segundo a WHO } \\
\text { (2003) }\end{array}$ & $\begin{array}{c}\text { Adequação (\%) } \\
\text { (com relação ao } \\
\text { valor mínimo) }\end{array}$ \\
\hline VET (Kcal) & $1199,72 \mathrm{kcal}$ & 1600 a $2200 \mathrm{Kcal}$ & $74,9 \%$ \\
Carboidratos (\% do VET) & $52,60 \%$ & $50 \%$ a $75 \%$ & $105,2 \%$ \\
Proteínas (\% do VET) & $16,24 \%$ & $10 \%$ a $15 \%$ & $162,4 \%$ \\
Lipídios (\% do VET) & $31,16 \%$ & $15 \%$ a $30 \%$ & $207,7 \%$ \\
\hline
\end{tabular}

$(p>0,05)$

verificado quanto à ingestão de carboidratos, que encontrou-se dentro da faixa de normalidade, segundo $\mathrm{WHO}^{13}$.

Mariz ${ }^{15}$ havia demonstrado que as bailarinas têm o hábito de consumir quatro a cinco refeições por dia, o que demonstrava uma adequação quanto ao fracionamento. No presente estudo, observou-se que $70 \%$ das bailarinas possuem o hábito de fazer quatro refeições, diariamente, sendo as mais freqüentes: o desjejum, almoço, lanche e jantar. A ceia foi a refeição menos referenciada.

\section{GRÁFICO 2 \\ DISTRIBUIÇÃO PERCENTUAL DA ADEQUAÇÃO DO CONSUMO DE MACRONUTRIENTES DAS BAILARINAS.}

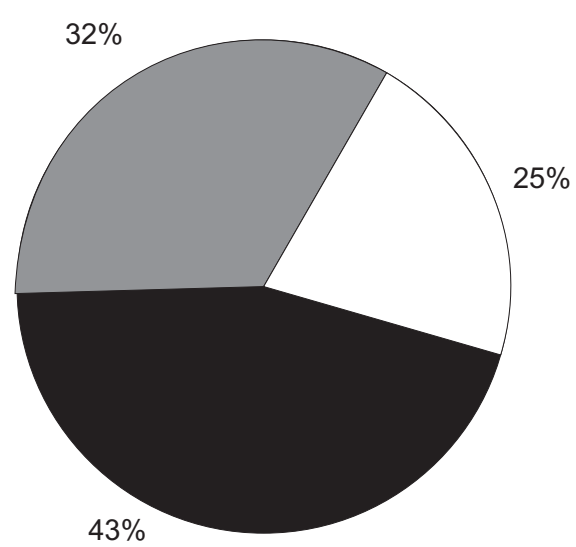

\section{CONCLUSÃO}

Conhecendo o perfil nutricional das bailarinas estudadas, pertencentes a um grupo autônomo da equipe Yalabina, do Rio de Janeiro, observou-se que este se apresenta adequado para metade delas, sendo, portanto, necessário orientá-las quanto a uma alimentação balanceada e aos riscos de restrições alimentares.

A avaliação da composição corporal é importante como indicador indireto do estado nutricional. No presente estudo, verificou-se que metade das bailarinas pesquisadas apresentava perfil antropométrico dentro da faixa de normalidade.

Ao se analisar o consumo alimentar, observou-se uma baixa ingestão de calorias e uma ingestão excessiva de proteínas e lipídios, que podem acarretar em menor desempenho durante a dança e em maior acúmulo de gordura abdominal. Tais resultados apontam a necessidade de um melhor acompanhamento nutricional, frente à prática do exercício, com ênfase na educação para a escolha adequada de alimentos, visando a correção de seus hábitos alimentares para prevenir futuras complicações.

A mulher está vulnerável a doenças e a condições que podem afetar a sua qualidade de vida e é cada vez mais comprovado que a Nutrição é um fator essencial na promoção da saúde. Ter uma alimentação adequada é uma das bases de uma vida saudável, ou seja, colabora para diminuir os riscos de adoecer e para a melhora da qualidade de vida.

\section{REFERÊNCIAS BIBLIOGRÁFICAS}

1. Arruda L. A dança oriental como ferramenta terapêutica. Disponível em: URL: <http:// www.khaanelkhalili.com.br/ artigos/dancadoventreartigos021.htm> (03 mar. 2006).

2. Faruk L. Anatomia e cinesiologia aplicada à Dança do Ventre. Disponível em: URL: <http:// www.lufaruk.cjb.net > (03 mar. 2006). 
3. Sol do Sahara. A magia da dança do ventre. A história da dança. Disponível em: URL: <http:// www.soldosahara.com.br/ dança.asp >(10 abr. 2006).

4. Cestari N. Ritmo e movimento que enfeitiça o público. Disponível em: URL:<http:// www.unifolha.com.br/materia/ ?id=27115 ( 24 mar. 2006).

5. Araújo ACM, Soares YNG. Perfil de utilização de repositores protéicos nas academias de Belém, Pará. Rer Nut 1999; 12(1):81-9.

6. Sichieri R, Everhart JE, Mendonça GAS. Diet and mortality from common cancars in Brazil: an ecological study. Cad Saúde Pública 1996; 39:298-309.

7. Almeida TA, Soares EA. Nutritional and anthropometric profile of adolescent volleyball athletes. Rev Bras Med Esporte 2003; 9(4).

8. Cuppari L. Nutrição clínica no adulto. São Paulo: Manole; 2002.

9. Shills ME, et al. Tratado de nutrição moderna na saúde e na doença. 9ª ed. São Paulo: Manole; 2003.

10. Navarro AM, Marcini JS. Uso de medidas antropométricas para estimar gordura corporal em adultos. Nutrire Rev Soc Bras Alim Nutr 2000;19/20:31-47.

11. Carvalho EB. Manual de suporte nutricional. Rio de Janeiro: Medsi; 1992.

12. Christakis G. Nutritional assessment in health programs. Am J Publ Health 2001; 63(Suppl): 1-82.

13. World Health Organization. Physical status: the use and interpretation of antropometry. Geneva:WHO Technical Report Series 854; 2003.

14. Food and Nutrition Board - Institute of Medicine. Dietary reference intake for energy, carbohydrate, fat, fatty acids, cholesterol, protein and amino acids. Washington, DC: National Academies Press; 2002.

15. Mariz R, Ito MK. Hábito alimentar e perfil nutricional de bailarinas entre 12 e 18 anos. In: $V$ Congresso Nacional da Sociedade Brasileira de Alimentação e Nutrição, 1999, São Paulo. Anais V Congresso Nacional da Sociedade Brasileira de Alimentação e Nutrição, 1999.

\section{Endereço para correspondência:}

Rua: Santo Afonso, 216 apto 803 - Tijuca Rio de Janeiro - RJ - Brasil CEP: 20511170 e-mail: nut_consult@yahoo.com.br 